\title{
Detecção de anticorpos contra Neospora caninum e Toxoplasma gondii em soros de bubalinos (Bubalus bubalis) no Estado de São Paulo, Brasil
}

\author{
Antibodies for Neospora caninum and Toxoplasma gondii in water buffaloes from \\ São Paulo State, Brazil
}

\author{
Luciano Melo de Souza ${ }^{1,2}$; Adjair Antonio do Nascimento ${ }^{2}$; Patricia Iriê Furuta2; \\ Lúcia Mara Souza Basso1; Daniela Miyasaka da Silveira1,2; Alvimar José da Costa ${ }^{2}$
}

\begin{abstract}
Resumo: Bubalinos são susceptíveis à infecção por Neospora caninum e Toxoplasma gondii, contribuindo assim para a disseminação destes protozoários na natureza. A ocorrência de anticorpos foi investigada em soro sangüíneo de bubalinos, utilizando-se a técnica de imunofluorescência indireta (IFI). Foram avaliados os fatores raça e idade dos búfalos, e também pesquisada a presença de anticorpos contra os dois parasitos em cães e humanos de convívio estreito com os bubalinos. Amostras de soros foram colhidas de búfalos $(n=411)$, cães $(n=8)$ e humanos ( $n=14)$, oriundos de propriedades com características leiteiras e examinadas em laboratório. Dentre os soros de bubalinos testados, $56,0 \%$ foram reagentes $(\geq 1: 200)$ para $N$. caninum e $49,9 \%$ reagiram $(\geq 1: 64)$ contra $T$. gondii. Mostraram-se reagentes aos dois protozoários $33,9 \%$ dos búfalos. Dos soros de cães $25,0 \%$ reagiram ao $N$. caninum ( $\geq 1: 50)$ e $62,5 \%$ contra o $T$. gondii ( $\geq 1: 16$ ). Nenhum soro humano mostrou-se reagente em níveis considerados positivos ( $\geq 100$ ) pela literatura revisada. As fêmeas, entre 5 e 6 anos de idade, apresentaram maior percentual de sororreagentes a $T$. gondii. Os resultados obtidos permitem inferir que tanto o Neospora caninum quanto o Toxoplasma gondii encontramse bastante disseminados entre os rebanhos investigados e que aparentemente a raça e a idade das fêmeas não interferiram na freqüência de indivíduos sororreagentes ao $N$. caninum.
\end{abstract}

Palavras-chave: Bubalus bubalis, Neospora caninum, Toxoplasma gondii, RIFI.

\begin{abstract}
Water buffaloes (Bubalus bubalis), are capable of becoming infected with Neospora caninum and Toxoplasma gondii, contributing to disease dissemination. The incidence of these antibodies was assessed in sera of water buffaloes, using an immunofluorescent antibody technique (IFAT). Any possible influence of breed or age of the buffaloes was investigated, besides assessment of sera antibody titres of any dogs and humans that were in close contact with the tested animals. Serum samples were taken from water buffaloes $(n=411)$, dogs $(n=8)$ and humans $(n=14)$, from buffalo dairy farms in the São Paulo State, and tested. Of the samples of buffalo sera tested, $56.0 \%$ were reactive ( $\geq 1: 200)$ to $N$. caninum and $49.9 \%$ were reactive $(\geq 1: 64)$ to $T$. gondii. Of all, $33.9 \%$ of the buffaloes presented antibody titres for both protozoon parasites. Of the canine serum samples, $25.0 \%$ presented titres $(\geq 1: 50)$ for $N$. caninum and $62.5 \%$ for $T$. gondii ( $\geq 1: 16)$. The human serum samples did not show detectable antibodies for $N$. caninum when using a $\geq 100$ limit titre for positive findings. The obtained data allows the conclusion that the protozoan parasite $N$. caninum, as well as $T$. gondii, are widely disseminated in the water buffalo herds assessed and, apparently, the factors breed and age do not interfere with frequency of $N$. caninum positives among adult female buffaloes. When concerning $T$. gondii, female buffaloes of 5 to 6 years of age showed more frequent presence of specific antibodies.
\end{abstract}

Key words: Neospora caninum, Bubalus bubalis, Toxoplasma gondii, Dog, Human, IFAT.

\section{Introdução}

Neospora caninum é um protozoário, parasito, pertencente ao filo Apicomplexa, família Sarcocystidae, subfamília Toxoplasmatinae. É possível que até 1988 , por sua similaridade estrutural e biológica com o Toxoplasma gondii, esse parasito tenha sido diagnosticado erroneamente e mantido oculto à luz das investigações científicas. A partir do isolamento em cães com neuropatia, foi descrito pela primeira vez por Bjerkas et al., em 1984, como um protozoário semelhante ao Toxoplasma e foi denominado N. caninum em 1988.

Desde então esse parasito foi descrito em várias espécies animais, apresentando ampla distribuição geográfica e, atualmente, é considerado o principal agente de abortamentos em bovinos em algumas regiões do mundo (COLLERY, 1996; DUBEY e LINDSAY, 1996; THURMOND e HIETALA, 1996). Os bubalinos são também susceptíveis à infecção pelo $N$. caninum.

A neosporose, doença causada pelo protozoário Neospora caninum (DUBEY et al., 1988), caracterizase por sintomatologia nervosa em cães e em bovinos jovens. Ainda que seja considerada enfermidade emergente nos Estados Unidos da América, Europa e Oceania, no Brasil existem incipientes informações sobre a real situação epidemiológica dessa doença.

Dentre os métodos desenvolvidos para o diagnóstico da neosporose, a detecção de anticorpos específicos no soro sangüíneo, por meio da técnica de RIFI,

${ }^{1}$ Aluno de pós-graduação da FCAV/UNESP, Jaboticabal.

${ }^{2}$ CPPAR - Centro de Pesquisas em Sanidade Animal,/FCAV/UNESP, Campus de Jaboticabal. 
utilizando como antígeno, taquizoítos de $N$. caninum, é largamente usada para os estudos epidemiológicos, por ser confiável e menos onerosa (TREES et al., 1994; PARÉ et al., 1995).

Segundo Dubey e Lindsay (1996), na RIFI existe a possibilidade de reação cruzada entre $N$. caninum e Toxoplasma gondii; sugerem, assim, que em estudos sorológicos deve-se pesquisar anticorpos para ambos os protozoários. No entanto, essas reações cruzadas são relativamente baixas ou nulas, já que nesse tipo de prova o que se avalia são os antígenos de superfície (TREES et al., 1994). Contudo, nos testes de ELISA, a reação cruzada pode ocorrer, já que são expostos os diversos antígenos presentes dentro do citoplasma do parasito, através da ruptura da membrana externa, e alguns deles são semelhantes entre as espécies.

Outros problemas já foram levantados no diagnóstico da neosporose, pela técnica da RIFI. Verificou-se que, em algumas amostras, pode ocorrer uma reação apical caracterizada pela fluorescência parcial dos taquizoítos (CONRAD et al., 1993; PARÉ et al., 1995); a forma como ocorre essa reação pode ser determinada pela ação inespecífica de vários anticorpos que estejam presentes no soro sangüíneo dos bovinos e que comumente aparecem após seu nascimento.

Huong et al. (1998), examinando 200 soros de bovinos e 200 de bubalinos de corte, no Vietnã, observaram $5,5 \%$ de bovinos e $1,5 \%$ de bubalinos com anticorpos detectáveis contra $N$. caninum. Foram utilizados para análise o iscom-ELISA com densidade óptica (DO) $\geq 0,20$ e RIFI, considerando positivos os soros com títulos $\geq 640$.

O primeiro estudo sorológico de $N$. caninum em búfalos do Egito foi realizado por Dubey et al. (1998) que registraram, de 75 exemplares investigados, utilizando o Neospora agglutination test (NAT), a presença de anticorpos contra $N$. caninun em $68,0 \%$ das amostras, nas seguintes diluições: 1:20 em 6 búfalos, 1:40 em 15; 1:160 e 1:320 em 1, e $\geq 1: 640$ em 28 animais.

$\mathrm{Na}$ Itália, examinando amostras de soro de 1.377 búfalos (Bubalus bubalis), oriundos de 50 propriedades rurais e utilizando a RIFI para detecção de anticorpos contra N. caninum, Guarino et al. (2000) detectaram $34,6 \%$ dos animais sororreagentes, observando, ainda, a presença de aborto e sintomas neurológicos em duas das 50 propriedades. Segundo a faixa etária, os percentuais de animais positivos foram: $24,5 \%$ para grupos de 1-2 anos, 32,2\% para grupos de $2-4$ anos, 38,6\% para grupos de 5-6 anos, e 43,1\% para grupos $>6$ anos. O ponto de corte estabelecido foi a diluição 1:200 e o conjugado contra lgG bubalino foi produzido em coelhos.

Gondim et al. (1999b) encontraram uma freqüência de anticorpos contra $N$. caninum de 36,5\% em 115 amostras de sangue colhidas de bubalinos criados no Estado da Bahia. Os autores utilizaram a RIFI para as análises e como ponto de corte, diluições $\geq 200$.

Fujii et al. (2001) encontraram em 222 amostras de soro de fêmeas bubalinas, pertencentes a 11 proprie- dades localizadas na região do Vale do Ribeira, Estado de São Paulo, 52,7\% de sororreagentes ao N. caninum pela Neospora agglutination test (NAT), com títulos $\geq$ 40 , e $63,9 \%$ reagentes pela RIFI com títulos $\geq 25$.

A toxoplasmose é uma importante zoonose de caráter cosmopolita, sendo elevada a prevalência da infecção pelo T. gondii, em seres humanos (DUBEY, 1996). São raros os estudos sobre a infecção toxoplásmica em búfalos, mas sabe-se que a prevalência de anticorpos contra $T$. gondii tem se apresentado mais baixa que em bovinos (DUBEY et al., 1998; HUONG et al., 1998; GONDIM et al., 1999a; FUJII, 2000.)

Os búfalos podem infectar-se com Neospora caninum pela ingestão de água e alimentos contaminados com oocistos eliminados nas fezes de felinos. O hábito dos búfalos de passarem a maior parte do tempo deitados em locais lodosos ou em aguadas longe do habitat dos gatos talvez explique a baixa infecção nessa espécie (NAVIDPOUR e HOGHOOGHI-RAD, 1998). Aliam-se a esse fato a baixa susceptibilidade dessa espécie à infecção pelo T. gondii e suas condições de manejo (HUONG etal., 1998). NAVIDPOUR e HOGHOOGHI-RAD (1998) sugerem que, em búfalos, parece ocorrer diminuição de anticorpos contra T. gondii com o aumento da idade.

Em estudos conduzidos por Dubey e Beattie (1988), a freqüência de ocorrência de anticorpos contra T. gondii em búfalos variou de 7 a 48,0\% em diferentes regiões do Egito, enquanto que na Indonésia foi zero, e na Turquia, de 48,0\%. Navidpour e Hoghooghi-Rad (1998) encontraram 8,8\% (34/385) de búfalos com anticorpos contra T. gondii com títulos $\geq 16$ pela RIFI, no Irã.

Dubey et al. (1998), no Egito, encontraram 67,0\% (50/75) de fêmeas bubalinas soropositivas para Neospora, a maioria com títulos baixos $\leq 64$ no dye test (DT), mas, pelo teste de aglutinação direta modificada ( $T$ MAT), apenas um animal apresentou título de 1:50. Huong et al. (1998) obtiveram 3,0\% (6/200) de amostras positivas, enquanto em bovinos, $10,5 \%$ (21/200), no sul do Vietnã, pelo teste de aglutinação direta; das seis amostras positivas, quatro apresentaram títulos considerados positivos na diluição do soro 1:50 e duas na diluição 1:2.500.

No Brasil existem três trabalhos publicados de ocorrência de anticorpos contra T. gondii em bubalinos, o de Gondim et al. (1999a), que encontraram 4/104 (3,9\%) dos búfalos sororreagentes e (2/194) 1,0\% dos bovinos positivos, níveis esses muito inferiores aos de ovinos e caprinos das mesmas propriedades, que foram de $18,8 \%$ e $28,9 \%$, respectivamente, utilizando teste de aglutinação em látex (LAT). O segundo é o de Barros et al. (1999), que, no Pará, encontraram, respectivamente, $12,2 \%(15 / 123)$ e $22,8 \%(28 / 123)$ de búfalos sorologicamente positivos, utilizando o ELISA e o LAT. A proporção de propriedades com animais infectados foi de $42,8 \%$ pelo teste ELISA, ou seja, seis das 14 fazendas examinadas e 71,4\% (10/14) pelo LAT.

Fujii (2000) encontrou, através da RIFI, 3,2\% de animais sororreagentes ao T. gondii com títulos $\geq 64$. 
Essas observações foram feitas em fêmeas bubalinas adultas pertencentes a 11 propriedades localizadas na região do Vale do Ribeira, São Paulo.

Existe uma grande variação de níveis de prevalência, em diferentes regiões do mundo, devendo-se, em parte, às diferentes técnicas empregadas, tornando os resultados não comparáveis (CHHABRA et al., 1985).

Em decorrência das perdas econômicas consideráveis causadas alhures pela neosporose na espécie bovina, e sua significante semelhança com a bubalina, devido ao manejo, há a possibilidade de contágio das mesmas enfermidades. Ainda, devido à escassez de informações epidemiológicas da doença no Brasil, principalmente na espécie proposta, e sua grande importância cosmopolita em hospedeiros poliespecíficos, responsável por grandes perdas econômicas na pecuária mundial, este trabalho objetivou o estudo sorológico de anticorpos contra $N$. caninum e T. gondii.

A pesquisa foi realizada por meio da técnica da imunofluorescência indireta (RIFI-IgG) em rebanhos bubalinos (Bubalus bubalis) leiteiros, independentemente do histórico de abortamentos. Foram investigados, ainda, quanto à presença de anticorpos contra $N$. caninum e contra $T$. gondii, cães e seres humanos de estreito convívio com os bubalídeos.

\section{Material e Métodos \\ 2.1 Delineamento e local experimental}

Para estipular a amostra experimental estatisticamente significante de animais examinados, foi utilizada a "Distribuição de Poisson" (CÔRTES, 1993), para eventos raros. Desta forma, o número de amostras de sangue colhidas foi baseado na hipótese de baixa reatividade sorológica dos bubalinos aos dois parasitos em questão.

Foram obtidas 411 amostras de sangue de bubalinos, em idade reprodutiva, oriundos de 12 rebanhos pertencentes a propriedades distribuídas em 12 municípios. As propriedades investigadas pertencem aos seguintes municípios: Sales de Oliveira, Marília, Votuporanga, Dourado, Pirassununga, Franca, Bocaina, Botucatu, Analândia, Araçatuba, Ibitinga e Jaboticabal.

O total de bubalinos de onde foram obtidas as 411 amostras (1.319 búfalos) corresponde a $3,85 \%$ do rebanho total do Estado de São Paulo, segundo dados do ANUALPEC 2000. Ainda foram colhidas amostras de sangue de cães $(n=8)$ e seres humanos $(n=14)$ conviventes com os bubalinos.

\subsection{Amostras sangüíneas}

Foram colhidos, através de punção da veia jugular e/ou mamária, cerca de $15 \mathrm{~mL}$ de sangue, sem anticoagulante, de cada animal do grupo experimental. Após obtenção, os soros foram distribuídos em tubos "eppendorf", identificados e mantidos à temperatura de $-20^{\circ} \mathrm{C}$ até a realização dos testes sorológicos.
Soros humanos foram obtidos após colheita de sangue individual, realizada por profissional da área de Saúde Humana.

\subsection{Análises sorológicas 2.3.1 Antígenos}

a) Neospora caninum

Para a pesquisa de anticorpos contra N. caninum, foram adquiridas, comercialmente, lâminas contendo taquizoítos íntegros de N. caninum da cepa Nc-1, produzidos em cultivo celular de células Vero, pelo Veterinary Medical Research and Development Inc. (VMRD), de Pullman-USA, Lote: V-99060B, distribuídos em lâminas para imunofluorescência com 12 poços. As lâminas, contendo o substrato antigênico, foram conservadas a $-20 \% \mathrm{C}$ até o momento do uso.

b) Toxoplasma gondii

A amostra de Toxoplasma gondii (cepa $\mathrm{RH}$ ) utilizada vem sendo mantida por passagens de exsudato peritoneal de camundongos albinos (Mus musculus) em laboratório do "Centro de Pesquisas em Sanidade Animal” (CPPAR).

Na preparação do substrato antigênico utilizou-se uma suspensão de taquizoítos de T. gondii obtidos por lavado intraperitoneal de camundongos com solução salina $0,85 \%$ estéril. A suspensão de taquizoítos foi lavada por três vezes consecutivas em solução salina $0,85 \%$ estéril a 2.500 rpm por 10 minutos. O sedimento foi ressuspenso em solução salina $0,85 \%$, contendo formalina a $2 \%$ e permaneceu em estufa a $37^{\circ} \mathrm{C}$ por 30 minutos, sendo agitado por inversão, delicadamente, a cada 10 minutos. Após fixação, os taquizoítos foram lavados por três vezes com solução salina $0,85 \%$, ajustando-se a concentração final de modo a haver de 20 a 30 parasitos por campo microscópico em aumento de 400x. O antígeno foi distribuído em lâminas, as quais foram embaladas e estocadas $\mathrm{a}-20^{\circ} \mathrm{C}$ até o momento de uso. A metodologia foi a mesma preconizada por Camargo (1964).

\subsection{Provas sorológicas \\ 2.4.1 Reação de Imunofluorescência Indireta (RIFI)}

Soros de bubalinos $(n=411)$, de cães $(n=8)$ e de humanos ( $n=14)$ foram previamente triados em diluição única, e os que apresentavam reatividade foram titulados frente aos antígenos de N. caninum e T. gondii.

\section{a) RIFI-Neospora caninum}

As amostras de soro bubalino foram submetidas à reação de imunofluorescência indireta (RIFI), segundo metodologia preconizada por Conrad et al. (1993). Cada soro foi diluído na base dois, iniciando-se com 1:200, em solução salina tamponada com fosfatos, e pH 7,2.

Soros controles positivos e negativos foram diluídos conforme a descrição acima. Em cada cavidade da 
lâmina, contendo o substrato antigênico, colocaramse $15 \mathrm{~mL}$ de amostra sob estudo, sendo incubada por 30 minutos à temperatura de $37^{\circ} \mathrm{C}$ em câmara úmida.

Após incubação, cada lâmina foi submetida a três lavagens de 5 minutos cada, em uma cuba de vidro contendo tampão carbonato, $\mathrm{pH} 9,0$.

As lâminas foram secas à temperatura ambiente, $e$ em cada cavidade foi acrescentado o conjugado (IgG de coelho contra IgG de bovino, marcada com isotiocianato de fluoresceína -Sigma/F-7887), utilizado na diluição de 1:200 em PBS, contendo azul de Evans a $0,01 \%$. As lâminas foram novamente incubadas por 30 minutos a $37^{\circ} \mathrm{C}$, em câmara úmida, retiradas, secas ao ar e montadas com lamínula, utilizando-se glicerina tamponada ( $\mathrm{pH} 8,0$ ) em uma relação de 9:1 de glicerina/ tampão. A leitura foi realizada em microscópio equipado para fluorescência (Sistema de epi-iluminação - objetiva 40x). As reações com título igual ou maior que 200 foram consideradas positivas (GONDIM et al., 1999b, GUARINO et al., 2000).

Reações em que os taquizoítos apresentavam fluorescência periférica total (PARÉ et al., 1995) foram consideradas positivas.

Procedimento idêntico ao descrito acima foi aplicado aos soros de cães e de seres humanos, utilizandose como conjugados, respectivamente, a lg $G$ de coelho contra IgG de cão e $\lg G$ de camundongo contra $\lg G$ humano (Sigma/F-7884 e Sigma/F-5512).

\section{b) RIFI - Toxoplasma gondii}

A técnica utilizada foi a descrita por Camargo (1964), assim resumida: as lâminas, contendo o substrato antigênico, foram descongeladas à temperatura ambiente. Inicialmente foi realizada uma triagem de cada soro nas diluições de 1:16 e de 1:64. As amostras positivas na diluição 1:64 foram novamente testadas em diluições seqüenciais na base quatro até 1:4.096.

Os soros testes e controles positivo e negativo foram diluídos em solução salina tamponada com fosfato 0,1 $\mathrm{M}$ (PBS) de $\mathrm{pH} 7,2$. Em cada cavidade da lâmina pipetaram-se $15 \mathrm{~mL}$ de cada soro. Após 40 minutos de incubação à temperatura de $37^{\circ} \mathrm{C}$ em câmara úmida, realizaram-se três lavagens de cada lâmina por 10 minutos em uma cuba de vidro contendo PBS. Após a secagem das lâminas, à temperatura ambiente, foi acrescentado, em cada cavidade, o conjugado $\lg G$ de coelho contra IgG bovina marcada com isotiocianato de fluoresceína (Sigma/F-7887), previamente diluído a 1:200, em solução de PBS contendo azul de Evans $0,01 \%$. Após 30 minutos, em câmara úmida, a $37^{\circ} \mathrm{C}$ foram lavadas e montadas.

A leitura foi efetuada em microscópio equipado para fluorescência, sistema de epi-iluninação e visualização com objetiva de 40x. As reações com título igual a ou maior que 64 foram consideradas positivas (COSTA et al., 1977). Conjugados anti-cão e anti-humano foram utilizados conforme indicação do fabricante, seguindo a técnica de Camargo (1964).

\section{Resultados \\ 3.1 Cães e humanos}

De oito soros caninos testados, apenas dois $(25,0 \%)$ mostraram níveis detectáveis e considerados positivos para Neospora caninum, enquanto cinco $(62,5 \%)$ foram reagentes em níveis considerados positivos contra 0 Toxoplasma gondii.

Os soros humanos não reagiram ao $N$. caninum $(00,0 \%)$ em níveis considerados positivos e $50,0 \%$ desses mesmos soros reagiram ao Toxoplasma gondii. No entanto, foram encontrados soros de humanos reagentes ao Neospora caninum nas diluições de 1:16 e 1:64, não consideradas positivas para a espécie em questão, segundo literatura consultada.

Seis amostras de soro humano (42,8\%) apresentaram sororreatividade apical ao Neospora caninum, em título de 16, não considerado positivo.

De oito cães investigados, cinco $(62,50 \%)$ mostraram-se sororreagentes (títulos $\geq 64$ ) contra $T$. gondii, e três $(37,5 \%)$ reagiram em diluição 1:16. Apenas dois dos 8 cães mostraram-se reagentes contra Neospora caninum nas diluições 1:50 e 1:100 respectivamente.

\subsection{Bubalinos}

A Tabela 1 apresenta os resultados numéricos e percentuais da ocorrência de anticorpos contra $N$. caninum e contra $T$. gondii nos soros dos búfalos investigados.

Das 411 amostras de soros bubalinos analisadas pela RIFI, para a investigação de prováveis animais sororreagentes contra Neospora caninum, 230 (56,0\%) resultaram positivas, com títulos iguais a ou maiores que 200, e $205(44,0 \%)$ delas mostraram-se não reagentes (Tabela 1 ).

As mesmas 411 amostras de soro colhidas dos bubalinos, submetidas à prova de imunofluorescência indireta (RIFI) para T. gondii, apresentaram 205 (49,9\%) sororreagentes com títulos iguais ou superiores a 64 , considerados positivas.

Arecíproca dos títulos de anticorpos contra $N$. caninum e $T$. gondi, subdividindo os animais em sexo e grupo etário a que pertencem, está discriminada na Tabela 1.

Encontrou-se alto percentual $(77,7 \%)$ de reprodutores com anticorpos para $N$. caninum, seguidos de bezerros menores de um ano $(65,4 \%)$ e fêmeas maiores de 24 meses (52,16\%). Dentre os bubalinos em estudo, $24,6 \%$ apresentaram títulos $\geq 800$. 
Os percentuais de animais (reprodutores, bezerros e fêmeas adultas) sororreagentes ao $T$. gondii mostraram-se equiparáveis aos encontrados nos mesmos animais para $N$. caninum. Apenas $1,1 \%$ dos búfalos apresentou reatividade ao T. gondii em títulos de 4.096.

A Figura 1 ilustra os valores absolutos e percentuais de fêmeas sororreagentes, distribuídas segundo a faixa etária a que pertencem (2-4, 5-6 e >6 anos).

Entre dois e quatros anos de idade, $50,0 \%$ das fêmeas apresentaram anticorpos contra $N$. caninum enquanto $39,2 \%$ apresentaram anticorpos para $T$. gondii. Entre 5 e 6 anos, foi encontrado maior número de fêmeas portadoras de anticorpos para T. gondii (62,5\%) do que para $N$. caninum $(53,8 \%)$.

Não houve diferenças discrepantes para os percentuais de ocorrência de anticorpos contra $N$. caninum entre as fêmeas em diferentes faixas etárias. Já, quanto ao $T$. gondii, o grupo de fêmeas com idade variando de cinco a seis anos mostrou maior número de indivíduos reagentes em relação aos outros dois grupos.

A Tabela 2 subdivide os bubalinos adultos (machos e fêmeas $\geq$ de 24 meses) em raças e seus respectivos percentuais de ocorrência de sororreagentes aos dois parasitas.
Dentre as raças em estudo, a Jafarabadi e a Murrah, respectivamente, foram as que apresentaram menor e maior percentual de animais sororreagentes ao $N$. caninum. A raça Mediterrânea e o grupo de animais mestiços equipararam-se nos valores percentuais de indivíduos positivos para anticorpos contra N. caninum.

Quanto à ocorrência de animais portadores de anticorpos contra T. gondii, o grupo da raça Mediterrânea foi o menos reagente, enquanto que os demais grupos mostraram percentuais semelhantes. Quando analisados, comparativamente, resultados obtidos para $N$. caninum e para $T$. gondii, nota-se maior ocorrência de animais portadores de anticorpos contra N. caninum.

A Figura 2 ilustra os percentuais de animais jovens ( $\leq 24$ meses) sororreagentes ao $N$. caninum e ao $T$. gondi, divididos em dois grupos etários de observação (0-2 meses e $\geq 3$ meses). Os animais situados no grupo etário de zero a dois meses mostraram-se mais reagentes contra $N$. caninum, porém, para ambas as faixas etárias os coeficientes encontrados permaneceram altos, superando os $50,0 \%$.

Para T. gondii não foi notada diferença entre os percentuais de ocorrência de animais sorreagentes.

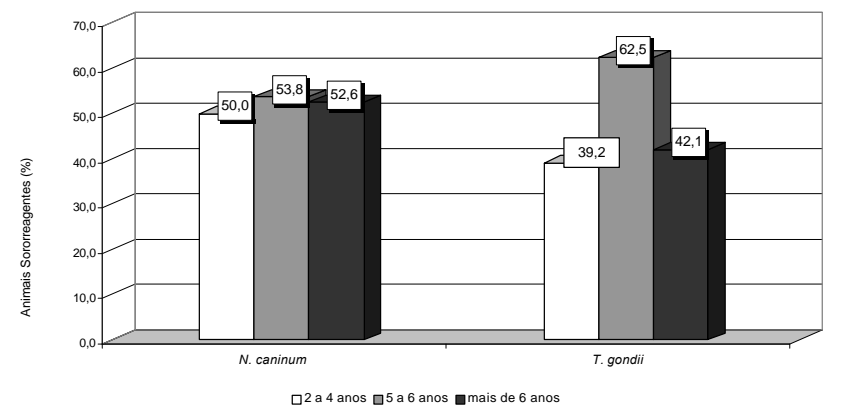

Figura 1 - Percentuais de fêmeas bubalinas, adultas, entre 2 e 14 anos, reagentes contra Neospora caninum e contra Toxoplasma gondii, distribuídas em três grupos etários, Estado de São Paulo.

Tabela 1 - Número de animais, percentuais de ocorrência e recíproca dos títulos de anticorpos contra Neospora caninum e Toxoplasma gondii em soros de búfalos (Bubalus bubalis) do Estado de São Paulo.

\begin{tabular}{|c|c|c|c|c|c|c|c|c|c|c|c|c|c|c|c|c|c|c|c|}
\hline & \multirow{3}{*}{ Número } & \multirow{2}{*}{\multicolumn{4}{|c|}{ Amostras Reagentes }} & \multicolumn{14}{|c|}{ Títulos } \\
\hline & & & & & & \multicolumn{6}{|c|}{ Neospora caninum } & \multicolumn{8}{|c|}{ Toxoplasma gondii } \\
\hline & & $\begin{array}{c}N . \\
\text { caninum }\end{array}$ & $\%$ & $\begin{array}{c}T . \\
\text { gondii }\end{array}$ & $\%$ & $200^{*}$ & $\%$ & 400 & $\%$ & 800 & $\%$ & $64^{\star *}$ & $\%$ & 256 & $\%$ & 1.024 & $\%$ & 4.096 & $\%$ \\
\hline Búfalos & 411 & 230 & 56,0 & 205 & 49,9 & 90,0 & 39,0 & 84,0 & 36,4 & 56,0 & 24,6 & 133 & 65,0 & 63 & 30,6 & 7 & 3,3 & 2 & 1,1 \\
\hline Reprodutores & 9 & 7 & 77,8 & 8 & 88,9 & 7,0 & 100,0 & 0,0 & 0,0 & 0,0 & 0,0 & 7 & 87,4 & 1 & 12,5 & 0 & 0,0 & 0 & 0,0 \\
\hline $\begin{array}{l}\text { Fêmeas } \\
\text { adultas }\end{array}$ & 301 & 157 & 52,2 & 145 & 48,2 & 63,0 & 40,4 & 61,0 & 39,0 & 33,0 & 20,6 & 96 & 66,2 & 45 & 30,9 & 3 & 2,2 & 1 & 0,7 \\
\hline Bezerros & 101 & 66 & 65,4 & 52 & 51,5 & 20,0 & 29,8 & 20,0 & 29,8 & 26,0 & 40,4 & 29 & 55,9 & 17 & 32,4 & 5 & 8,8 & 1 & 2,9 \\
\hline
\end{tabular}


Tabela 2 - Números absolutos e percentuais de bubalinos, adultos das raças Jafarabadi, Murrah, Mediterrânea e seus mestiços, sororreagentes para Neospora caninum e Toxoplasma gondii, Estado de São Paulo.

\begin{tabular}{|c|c|c|c|c|c|c|c|c|c|c|c|}
\hline & \multirow{3}{*}{ Sexo } & \multicolumn{4}{|c|}{ Reagentes } & \multicolumn{4}{|c|}{ Não Reagentes } & \multirow{2}{*}{\multicolumn{2}{|c|}{ Total }} \\
\hline & & \multicolumn{2}{|c|}{ N. caninum } & \multicolumn{2}{|c|}{ T. gondii } & \multicolumn{2}{|c|}{ N. caninum } & \multicolumn{2}{|c|}{ T. gondii } & & \\
\hline & & NAE & $\%$ & NAE & $\%$ & NAE & $\%$ & NAE & $\%$ & NTAE & $\%$ \\
\hline \multirow{3}{*}{ 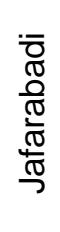 } & Fêmeas & 22 & 53,7 & 17 & 41,5 & 19 & 46,3 & 24 & 58,5 & 41 & 95,3 \\
\hline & Machos & 2 & 100,0 & 2 & 100,0 & 0 & 0,0 & 0 & 0,0 & 2 & 4,7 \\
\hline & Total & 24 & 55,8 & 19 & 44,2 & 19 & 44,2 & 24 & 55,8 & 43 & 100,0 \\
\hline \multirow{3}{*}{ 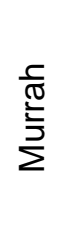 } & Fêmeas & 59 & 68,6 & 29 & 33,7 & 27 & 31,4 & 57 & 66,3 & 86 & 95,6 \\
\hline & Machos & 4 & 100,0 & 4 & 100,0 & 0 & 0,0 & 0 & 0,0 & 4 & 4,4 \\
\hline & Total & 63 & 70,0 & 33 & 36,7 & 27 & 30,0 & 57 & 63,3 & 90 & 100,0 \\
\hline \multirow{3}{*}{ 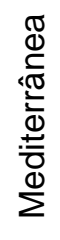 } & Fêmeas & 29 & 70,7 & 13 & 31,7 & 12 & 29,3 & 28 & 68,3 & 41 & 93,2 \\
\hline & Machos & 0 & 0,0 & 1 & 33,3 & 3 & 100,0 & 2 & 66,7 & 3 & 6,8 \\
\hline & Total & 29 & 65,9 & 14 & 31,8 & 15 & 34,1 & 30 & 68,2 & 44 & 100,0 \\
\hline \multirow{2}{*}{ 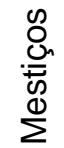 } & Fêmeas & 90 & 67,7 & 54 & 40,6 & 43 & 32,3 & 79 & 59,4 & 133 & 100,0 \\
\hline & Total & 90 & 67,7 & 54 & 40,6 & 43 & 32,3 & 79 & 59,4 & 133 & 100,0 \\
\hline
\end{tabular}

NAE: Número de animais examinados

NTAE: Número total de animais examinados

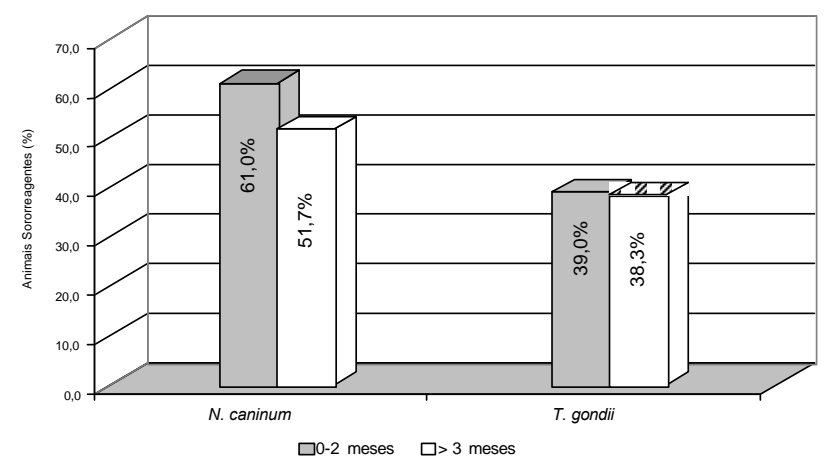

Figura 2 - Percentuais de bezerros ( $\leq 24$ meses), subdivididos em duas faixas etárias $(0-2$ e $>3$ meses), sororreagentes para Neospora caninum e Toxoplasma gondii, Estado de São Paulo. 


\section{Discussão}

A reação de imunofluorescência (RIFI) foi o método diagnóstico de eleição para detecção dos anticorpos específicos contra $N$. caninum no soro dos bubalinos por ser confiável, bastante específico e menos oneroso, como afirmam Trees et al. (1994) e Paré et al. (1995).

Seguindo as indicações de Dubey e Lindsay (1996), que sugerem a possibilidade de reações cruzadas entre $N$. caninum e $T$. gondii, foram realizadas provas para ambos os parasitos. Entretanto, não foram notadas reações cruzadas que, segundo Tree et al. (1994), são relativamente baixas já que nesse tipo de prova imunológica se avaliam os antígenos de superfície, específicos para cada espécie.

Quando se utiliza o teste de ELISA, as reações cruzadas são mais comuns, sendo necessário considerar pontos de corte mais elevados (HUONG et al., 1998).

As reações apicais, inespecíficas, caracterizadas por fluorescência parcial dos taquizoítos, como descrevem Conrad et al. (1993) e Paré et al. (1995), foram observadas também neste estudo e não trouxeram problemas na interpretação dos resultados, já que foram consideradas positivas as amostras com fluorescência em toda a superfície do taquizoito.

Os percentuais de ocorrência de bubalinos portadores de anticorpos contra $\mathrm{N}$. caninum no mundo variam de 1,5 a $68,0 \%$, mostrando uma grande discrepância, provavelmente relacionada à falta de padronização de técnicas e pontos discriminativos utilizados.

Dentre as poucas investigações sorológicas para detecção de anticorpos contra $N$. caninum em búfalos, apenas duas (GONDIM et al., 1999b e GUARINO et al., 2000), são passíveis de concordância total em utilização de técnica (RIFI) e ponto discriminativo $(\geq 200)$ utilizado. Fujii et al. (2001), realizaram estudo semelhante a este porém os pontos discriminativos utilizados foram diferentes $(\geq 25)$.

As variações em técnicas utilizadas e os pontos de corte adotados por diferentes autores dificultam a comparação de resultados. Não existe consenso entre pesquisadores de um ponto de corte ideal para identificação de um bubalino infectado por $N$. caninum. Foram observados, na literatura investigada, pontos discriminativos que variaram entre títulos de 25 a 200 para RIFI, 40 para NAT, e 640 para ELISA.

A freqüência de ocorrência de bubalinos portadores de anticorpos contra $N$. caninum, observada no presente trabalho, foi de $56,0 \%$ (Tabela 1) pela RIFI, para títulos $\geq$ 200 , valor esse pouco inferior aos registrados por Fujii et al. (2001), no Vale do Ribeira, São Paulo, que encontrou, por meio da mesma técnica $63,9 \%$ dos animais positivos e $52,7 \%$ positivos através do NAT.

Apesar de encontrado valor similar ao deste trabalho, os pontos de corte (RIFI / $\geq 25$ e NAT/ $\geq 40$ ) utilizados por Fujii et al. (2000) são bastante divergentes quando comparados aos utilizados nesta investigação. Se o autor tivesse adotado o título mínimo de 200, utilizado por Gondim et al. (1999b) e Guarino et al. (2000), os resultados provavelmente teriam sido inferiores. No entanto, o Vale do Ribeira é uma região de grande concentração de bubalinos, fato esse que poderia auxiliar na transmissão e disseminação do agente entre os rebanhos, o que justificaria tão relevante ocorrência.

Os $36,5 \%$ de búfalos sororreagentes encontrados por Gondim et al. (1999a), na Bahia, usando a mesma técnica (RIFI), possibilitam a hipótese de que a prevalência da neosporose oscile nos diversos estados brasileiros.

Guarino et al. (2000), na Itália, encontraram, por meio da RIFI e utilizando ponto de corte $\geq 200$ e mesmas diluições (1:200, 1:400 e 1:800), 34,6\% de bubalinos soropositivos para $N$. caninum, valor inferior aos encontrados nos 12 municípios aqui avaliados.

Foi observada a maior ocorrência de animais positivos para $N$. caninum entre os reprodutores $(77,7 \%)$ que, apesar de serem em menor número, mostraramse reagentes. Tal fato pode ser vinculado à contaminação do alimento por eles consumido, estocado nas proximidades das casas onde circulam cães, ou ainda podem esses animais ter adquirido o agente por via congênita.

Nenhuma bibliografia sobre a prevalência de $N$. caninum em bubalinos reprodutores foi encontrada.

Em seguida encontrou-se alto número de bezerros entre zero a 24 meses $(65,3 \%)$ sororreagentes. Era de se esperar que os bezerros jovens (zero-3 meses) refletissem os resultados encontrados para as fêmeas progenitoras, pela ingestão do colostro e conseqüentemente a imunidade passiva, e tal fato foi realmente observado. Dentre os bezerros acima de três meses e um ano de idade, 51 , \% foram reativos ao $N$. caninum.

Esses achados estão de acordo com Anderson et al. (1997), que observaram a transmissão vertical de $N$. caninum em novilhas que se infectaram por via transplacentária. Estas foram saudáveis quando jovens e quando adultas, mesmo assim transmitiram o parasita ao feto, caracterizando a importância da manutenção de $N$. caninum no rebanho. Concordam, ainda, com Paré et al. (1996), que constataram que mais de $80,0 \%$ de bezerros nascidos de vacas sorologicamente reagentes ao $N$. caninum também apresentavam anticorpos contra o mesmo parasito.

As fêmeas bubalinas apresentaram $52,1 \%$ de animais reagentes contra $N$. caninum. Essas, subdivididas em grupos etários, foram analisadas separadamente, e os resultados encontrados (2-4 anos $=50,0 \%$; $5-6$ anos $=53,8 \%$ e $>6$ anos $=52,6 \%$ ) diferiram dos encontrados por Guarino et al. (2000), na Itália (2-4 anos $=32,2 \% ; 5-6$ anos $=38,6 \%$ e $>6$ anos $=52,6 \%$ ).

Quando comparados proporcionalmente os percentuais encontrados em bubalinos adultos ( $>2$ anos) por Guarino et al. (2000), os valores obtidos neste estudo não divergem em números percentuais quanto à ocorrência de anticorpos entre os grupos avaliados. 
Thornton et al. (1994) notaram que na Nova Zelândia os abortos por $N$. caninum eram comuns em fêmeas com mais de quatro anos o que não foi objeto de avaliação neste estudo.

Pode-se notar a coabitação de outras espécies com os bubalinos, em especial cães (hospedeiros definitivos do $N$. caninum) e bovinos, espécies bastante acometidas pela neosporose. Em todas a propriedades prevaleceu a produção leiteira, e em duas propriedades havia laticínios que recebiam leite de outras propriedades da região.

A presença de cães portadores de anticorpos contra $N$. caninum em fazendas está fortemente associada à alta prevalência dessa infecção em bovinos (SAWADA et al.,1998; WOUDA et al., 1999). O número de cães reagentes ao $N$. caninum $(25,0 \%)$ está dentro das variações observadas na literatura (BELO et al., 1999).

O coeficiente encontrado pode estar aliado ao baixo número de caninos examinados, porém pode ser indicativo de que o parasito se mantenha dentro do rebanho mesmo na ausência do hospedeiro definitivo. Outra possibilidade é a de que esses cães possam estar eliminando oocistos e que não apresentem imunidade detectável, como observou Dubey (1999).

Mainar-Jaime et al. (1999) atentaram para a possibilidade da infecção de bovinos por oocistos eliminados nas fezes dos cães, e vale ressaltar que, encontrada alarmante ocorrência de anticorpos contra $N$. caninum em bubalinos, a recíproca da infecção dos cães se alimentando com carne e restos abortivos destes bubalinos pode estar colaborando para a manutenção do ciclo biológico nas regiões investigadas.

Dentre os grupos raciais em estudo, notaram-se pequenas diferenças na ocorrência de portadores de anticorpos contra $N$. caninum (Tabela 2), e a raça que mostrou menor freqüência de anticorpos conta $N$. caninum foi a Jafarabadi, todavia nada pode ser afirmado sobre sua susceptibilidade, visto que a maior parte desse grupo de animais pertencia a uma mesma propriedade e não estava sob as mesmas condições ambientais e manejo que os demais animais, portanto os resultados obtidos podem ser casuais.

Gondim et al. (1999b) relataram a ocorrência simultânea de anticorpos contra os dois parasitos em bovinos. Dentre os bubalinos positivos, 33,9\% reagiram tanto para $N$. caninum quanto para $T$. gondii., indício de que, em alguns casos, os animais podem estar infectados concomitantemente pelos dois protozoários.

A ocorrência de bubalinos sororreagentes ao $T$. gondii diverge da maioria dos achados na literatura citada (HUONG et al., 1998; DUBEY et al., 1998; GONDIM et al., 1999a; FUJII, 2000). Ao contrário do que afirmam Navidpour e Hoghooghi-Rad (1998), a infecção de búfalos pelo $T$. gondii é bastante comum em algumas regiões.

Os resultados obtidos concordam com os $48,0 \%$ de bubalinos sororreagentes para T. gondii, encontrados por Dubey e Beattie (1988) na Turquia, porém foram muito superiores aos valores encontrados para mesma espécie por Gondim et al. (1999a), na Bahia, e por Fujii (2000), no Vale do Ribeira, São Paulo.

De maneira geral, é arriscado afirmar que o mesmo ocorra em todas as regiões. Nas doze propriedades localizadas no Estado de São Paulo, a realidade foi uma alta freqüência de animais positivos para anticorpos contra T. gondii.

Tal discrepância de achados incentiva novas investigações, visto que a maioria dos autores indica a toxoplasmose como pouco disseminada entre bubalinos, realidade esta não concordante com o observado.

Os percentuais de cães reagentes ao $T$. gondii estão concordantes com os obtidos por outros autores

A infecção pelo $T$. gondii está disseminada em humanos por todo o mundo (DUBEY e BEATTIE, 1988). Dubey (1996) afirma que aproximadamente $30,0 \%$ da população adulta dos Estados Unidos (USA) e do Reino Unido (UK) possui anticorpos contra esse parasito. Menciona ainda que a prevalência é maior em outras partes da Europa Central e da América do Sul. A alta ocorrência observada em humanos investigados neste estudo vêm ao encontro da afirmação de Dubey (1996).

Encontrar anticorpos contra o $\mathrm{N}$. caninum em humanos não confirma seu caráter zoonótico, mas permite afirmar que os indivíduos examinados entraram em contato com tal parasito (TRANAS et al.,1999). Nesta investigação foram encontradas baixas freqüências de anticorpos contra $N$. caninum em humanos conviventes com os búfalos, porém são necessárias novas investigações sobre $o$ assunto.

A ocorrência de elevado número de bubalinos (Bubalus bubalis) portadores de anticorpos contra os dois parasitos nas regiões investigadas foi supreendente.

A princípio se esperava que, para ambos os protozoários, o número de animais portadores de imunidade contra os mesmos fosse baixo. Não foi confirmada essa baixa ocorrência e sim uma ampla distribuição dos dois parasitos nos rebanhos em estudo e provavelmente nessas regiões do Estado de São Paulo.

Juntamente com o estudo realizado por Fujii (2000), o presente inquérito soma informações importantes sobre a situação da neosporose e toxoplasmose no Estado de São Paulo, no intuito de proporcionar bases de apoio científico a futuras investigações.

\section{Agradecimentos}

À FAPESP pelo suporte financeiro e à Médica Veterinária Liza Ogawa (M.Sc) pelo fundamental auxílio na realização das provas sorológicas para Toxoplasma gondii. 


\section{Referências Bibliográficas}

ANDERSON, M.L. et al.. Evidence of vertical transmission of Neospora sp.: infection in dairy cattle. J. Am. Vet. Med. Assoc. Schaumburg, v. 210, n.8, p.1169-1172, 1997.

ANUALPEC 2000: Anuário da Pecuária Brasileira. São Paulo: FNP Consultoria \& Comércio, 2000. p. 330.

BARROS, A.A.M; MOLNÁR, E.; CARVALHO, M. et al. ELISA e latex-aglutinação utilizados para detectar anticorpos antiToxoplasma gondii em diferentes animais domésticos. In: CONGRESSO BRASILEIRO DE MICROBIOLOGIA, 20, Salvador, 1999. Anais... Salvador: Sociedade Brasileira de Microbiologia, 1999. p.143.

BELO, M.A.A.; REZENDE, P.C.B.; CASTAGNOLLI, K.C. Pesquisa de anticorpos anti-Neospora caninum em cães criados sob diferentes condições sanitárias. In: SEMINÁRIO BRASILEIRO DE PARASITOLOGIA VETERINÁRIA, 11, 1999, Salvador-BA. Anais... Salvador: Colégio Brasileiro de Parasitologia Veterinária, 1999. p.228.

BJERKÅS, I.; MOHN, S.F.; PRESTHUS, J. Unidentified cystforming sporozoon causing encephalomyelitis and myositis in dogs. Z. Parasitenkd., Jena, v.70, p.271-274, 1984.

CAMARGO, M.E. Improved technique of indirect immunofluorescence for serological diagnosis of toxoplasmosis. Rev. Inst. Med. Trop., São Paulo, v.6, n.3, p.117-118, 1964

CHHABRA, M.B.; GUPTA, S.L.; GAUTAM, O.P. Toxoplasma seroprevalence in animals in Northern India. Int. J. Zoon., Taipei, v.12, p.136-142, 1985.

COLLERY, P. Neosporosis in domestic animals. Irish Vet. J., Dublin, v.49, p.152-156, 1996.

CONRAD, P.A.; SVERLOW, K., ANDERSON, M.A. et al. Detection of serum antibody responses in cattle with natural or experimental Neospora infections. J. Vet. Diag. Invest., Columbia, v.5, p.572-578, 1993.

CÔRTES, J.A. Indicadores da ocorrência de Doenças em Populações. In: Epidemiologia, conceitos e princípios fundamentais. São Paulo: Livraria Varela, 1993. p.155.

COSTA, A.J.; ARAÚJO, F.G.; COSTA, J.O., et al. Experimental infection of bovines with oocysts of Toxoplasma gondii. J. Parasitol, Lancaster, v. 63, n. 2, p. 212-218, 1977.

DUBEY, J.P., Neosporosis in cattle: biology and economic impact, Journal of the Am.. Vet. Med. Associa., Schaumburg, v. 214, n. 8, Abril, p. 1160-1163, 1999.

DUBEY, J.P. Strategies to reduce trasmission of Toxoplasma gondii to animals and humans. Vet. Parasitol., Amsterdam, v.64, p.65-70, 1996.

DUBEY, J.P.; BEATTIE, C.P. Toxoplasmosis of animals and man. Boca Raton: CRC Press, 1988. 200p

DUBEY, J.P.; LINDSAY, D.S. A review of Neospora caninum and neosporosis. Vet. Parasitol., Amsterdam, v.67, p.1-59, 1996.

DUBEY, J.P.; CARPENTER, J.L.; SPEER, C.A. et al. Newly recognized fatal protozoan disease of dogs. J. Am. Vet. Med. Assoc.,Schaumburg, v.192, p.1.269-1.285, 1988.

DUBEY, J.P.; ROMAND, S; HILALI, M. et al. Seroprevalence of antibodies to Neospora caninum and Toxoplama gondii in water buffaloes (Bubalus bubalis) from Egypt. Int. J. Parasitol., Elmsford, v.28, n.3, p.527-529, 1998.

FUJII, T.U. Freqüência de ocorrência de anticorpos contra Neospora caninum (DUBEY, CARPENTER, SPPER, TOPPER E UGGLA, 1998) em búfalas (Bubalus bubalis), no Vale do Ribeira, Estado de São Paulo. 2000. 79f. Dissertação (Mestrado) Faculdade de Medicina Veterinária e Zootecnia, Universidade de São Paulo, São Paulo, 2000.

FUJII, T.U.; KASAI, N.; NISHI, S. M.; DUBEY, J. P.; GENNARI, S. M. Seroprevalece of Neospora caninum in female water buffaloes (Bubalus bubalis) from southeastern region of Brazil, Vet. Parasitol., Amsterdam, v.99, p. 331-334, 2001.

GONDIM, L.F.P.; BARBOSA, H.V.; RIBEIRO FILHO, C.H.A. et al. Serological survey of antibodies to Toxoplasma gondii in goats, sheep, cattle and water buffaloes in Bahia State, Brazil. Vet. Parasitol., v.82, Ámsterdam, p. 273-276, 1999a.

GONDIM, L.F.P.; SOUZA, R.M.; GUIMARÃES, J.E. et al. Freqüência de anticorpos contra Neospora caninum em búfalos criados no Estado da Bahia. In: SEMINÁRIO BRASILEIRO DE PARASITOLOGIA VETERINÁRIA, 11, 1999, Salvador-BA. Anais... Salvador: Colégio Brasileiro de Parasitologia Veteriná-ria, 1999b. p. 227.

GUARINO, A.; FUSCO, G.; SAVINI, G. et al. Neospora in water buffalo (Bubalus bubalis) in southern Italy. Vet. Parasitol., Amsterdam, v.91, p.15-21, 2000.

HUONG, L.T.T.; LJUNGSTROM, B.L.; UGGLA, A. et al. Prevalence of antibodies to Neospora caninum and Toxoplasma gondii in cattle and water buffaloes in southern Vietnam. Vet. Parasitol., v.75, Amsterdam, p.53-57, 1998.

MAINAR-JAIME, R.C., THURMOND, M.C., BERZALHERRANZ, B., Seroprevalence of Neospora caninum and abortion in dairy cows in northern Spain. Vet Rec, London, v. 145 , p. $72-75,1999$.

NAVIDPOUR, Sh.; HOGHOOGHI-RAD, N. Seroprevalence of anti-Toxoplasma gondii antibodies in buffaloes in Khoozestan province, Iran. Vet. Parasitol., Amsterdam, v.77, p.191-194, 1998.

PARÉ, J.; HIETALA, S.K.; THURMOND, M.C. Interpretation of an indirect fluorescent antibody test for diagnosis of Neospora sp. Infection in cattle. J. Vet. Diag. Invest., Columbia, v.7, p.273-275, 1995.

PARÉ, J.; THURMOND, M.C., HIETALA, S.K. Congenital Neospora caninum infection in dairy cattle and associated calfhood mortality. Can. J. Vet. Res., Ottawa, v. 60, n.2, p. 133-139, 1996.

SAWADA, M., PARK, C.H., KONDO, H., Serological survey of antibody to Neospora caninum in Japanese dogs. $J$ Vet Med Sci, Tokyo, v. 60, n. 07, p. 853-854, 1998.

THURMOND, M.C.; HIETALA, S.K. Culling associated with Neospora caninum infection in dairy cows. Am. J. Vet. Res., Chicago, v.57, p.1559-1562, 1996.

THORNTON, R.N.; GAJADHAR, A.; EVANS, J. Neospora abortion epidemic in a dairy herd. N. Z. Vet. J., Wellington, v. 42, p.190-191, 1994.

TRANAS, J.; HEINZEN, R.A.; WEISS, L.M. Serological evidence of human infection with the protozoan Neospora caninum. Clin. Diag. Lab. Immunol., Washington, v.6, n.5, p.765-767, 1999. 
TREES, A.J.; GUY, F.; LOW, J.C. et al. Serological evidence implicating Neospora species as a cause of abortion in British cattle. Vet. Rec.,London, v.134, p.405-407, 1994.

WOUDA, W., DIJKSTRA, T., KRAMER, A.M., Seroepidemiological evidence for a relationship between Neospora caninum infections in dogs and cattle. Int $J$ Parasitol, Elmsford, v. 29, n. 10, p. 1677-1682, 1999. 